\title{
Writing up and presenting qualitative research in family planning and reproductive health care
}

\author{
Emma Pitchforth, Maureen Porter, Edwin van Teijlingen, Karen Forrest Keenan
}

\section{Introduction}

This fourth and final paper on qualitative methods discusses the different ways that qualitative findings can be presented. We address the following topics: when to start writing up, considering the intended audience and the structure of the report/paper. We stress the value of being transparent and reflexive when writing up qualitative results. Although we have confined ourselves largely to written results, as this is the most common way of presenting findings, we briefly highlight some issues related to reporting photographic or videotaped data.

\section{When to write}

Writing is often considered the final stage of research, involving presentation of the completed study. It is often required at this stage to disseminate findings and meet the requirement of funding bodies. However, Richardson argues that 'in progress' writing is useful for focusing attention on important issues, which may have become sidelined during lengthy periods of fieldwork. ${ }^{1}$ Often researchers give presentations of work in progress to colleagues or conference audiences and these may serve the same purpose. Both quantitative and qualitative researchers aim to answer research questions using empirical data, but writing up qualitative research inevitably results in the emergence of new ideas and ways of viewing the data and hence plays a crucial role in the analysis process:

"I write because I want to find something out. I write in order to learn something that I didn't know before I wrote it ... not to write until I knew what I wanted to say, until my points were organized and outlined ... this static writing model coheres with mechanistic scientism and quantitative research ... It ignores the role of writing as a dynamic, creative process; it undermines the confidence of beginning qualitative researchers because their experience with research is inconsistent with the writing model."1

Often academics will tell you that they write several drafts or rewrite their paper several times. This is not simply to polish the style and make the words flow better; the actual writing helps to formulate ideas and, as such, is an intrinsic part of the ongoing analysis. Indeed, it is argued

J Fam Plann Reprod Health Care 2005; 31(2): 132-135

(Accepted 29 January 2005)

Department of Health Sciences, University of Leicester, Leicester, UK

Emma Pitchforth, BSc, PhD, Lecturer in Social Science and Health

Department of Obstetrics and Gynaecology, University of Aberdeen, Aberdeen, UK

Maureen Porter, MSc, PhD, Research Fellow

Dugald Baird Centre and Department of Public Health, Medical School, University of Aberdeen, Aberdeen, UK Edwin van Teijlingen, MEd, PhD, Reader in Public Health

Departments of Public Health and Medical Genetics, Medical School, University of Aberdeen, Aberdeen, UK Karen Forrest Keenan, MA, MLitt, Research Fellow

Correspondence to: Emma Pitchforth, Department of Health Sciences, University of Leicester, 22-28 Princess Road West, Leicester LE1 6TP, UK. E-mail: elp17@le.ac.uk that you can't start writing early enough, ${ }^{2}$ and then it is only when presenting a study publicly that 'flaws and problems appear' sometimes necessitating returning to the data. ${ }^{3}$

\section{Audience and purpose of writing}

It is useful to think about the intended audience before starting to write. The final report for the funding body will be very different from a paper for an academic journal or a book chapter, which in turn will be different from a onepage handout of the findings to be posted to the interviewees. Remember that academic journals differ in their audiences as well as submission requirements (e.g. word limit, layout, maximum number of tables, style of references, and so on). Experienced colleagues and reviewers can provide constructive criticism on drafts. Allow plenty of time between drafts for ruminating on the findings presented and reading relevant new material

The word limit in many journals is challenging, particularly for qualitative research because the data presented are usually in the form of quotations, which take up much of the word allowance. Rice and Ezzy ${ }^{4}$ suggested that one aspect of the findings should be presented in each paper to allow for more comprehensive articles, but this is not always realistic and risks an accusation of so-called 'salami slicing'! Fewer well-written and comprehensive papers may have more impact.

\section{Structure}

A standard structure for research reports or journal articles is to present an introduction, methods, results, discussion and conclusion. Sometimes it is hard to fit qualitative studies into this mould, as the results need to be discussed as they are presented. One possibility is to combine results/discussion into a findings section and then have a lengthy conclusion, which summarises the foregoing points. A paper examining autobiographies of multiple sclerosis patients omits all of the usual sections and combines results, analysis and discussion of relevant literature. 5 Although grounded theory studies can be difficult to fit into the standard format where a background literature review is required at the start of the paper, the study by Kumar et al. on antibiotics in general practice successfully integrated their literature review into the discussion. 6 The British Medical Journal, in its instructions to authors, highlights one possible way of presenting qualitative research: "You may find that presenting the results and discussion together, theme by theme, makes most sense."7

The methods section should convince the reader that the sample is appropriate and that the qualitative method selected is the best available for the problem studied. The theoretical framework, sampling strategy and fieldwork should be described in detail. ${ }^{8}$ Readers should be told which steps were taken to ensure the validity (truthfulness), reliability (repeatability) and generalisability of the results. ${ }^{9}$ If a thematic approach has been used, sections may be organised to represent different concepts. Methods are still made explicit but priority is given to the emerging themes. For ethnographic studies the write-up may be organised more like a story. ${ }^{10}$ For example, Leppard presented her ethnographic study of a hospital in Bangladesh as a notional day in the hospital ward.11 In practice, most write-ups are a mixture of the standard structure described and thematic structures. 
QUALITATIVE RESEARCH

\section{Using data in your argument}

Qualitative research depends to a large extent on producing a convincing account. ${ }^{12,13}$ It is standard practice to support the interpretation of data with quotations from field notes, interviews or focus group transcripts. It is important to determine whether a segment of data is integral to your argument or whether it merely provides an illustration of it. ${ }^{13}$ For example, during interviews women may give reasons for their contraceptive choices, which the researcher uses to categorise the women as different types of users. The quotes chosen may illustrate why they were coded and categorised as they were, or how women of a certain type constructively account for the choices they have made in the context of a research interview (i.e. why the data have been interpreted as they have). As a clear distinction must be made between the data and its interpretation, each requires a different approach to the text in which the quotes are embedded.

A central decision in writing up is selecting which data to include and which to omit. The relationship between the quotations included and those not included must be made explicit so that the reader can see how representative those selected are of the whole. This may be done numerically (e.g. 'eight out of ten interviewees saw the hospital redesign as a positive development') or qualitatively (e.g. 'this quotation is typical of those categorised as positive').

\section{Presentation of quotes}

Quotes have typically been presented within the text, usually indented from the main text and with single-line spacing. The danger with this type of presentation is that readers will skip over the text, and Richardson advises that quotations should be in the same type as the main text. The text should be constructed so that the lead-ins and lead-outs around the quotation entice the reader to read them as part of the text. ${ }^{1}$

Increasingly, tables or boxes are used to present data. ${ }^{14,15}$ These include all the quotes relating to a particular theme or opinion and can be useful when the word limit is restricted. Tables/boxes can also be used to summarise the different themes arising in comparison groups (e.g. between respondents in different countries or experience of patients with different diseases). ${ }^{16,17}$ Complex concepts are more difficult to present in a bulletstyle format but, depending on the purpose of the paper, this may be an effective way of supporting an argument and more likely to be read.

It is customary to use unique identifiers for each quote. For example, a focus group study of parents attending antenatal classes in different areas might identify a Liverpool mother as (Liv1F) or (Group 1 Liverpool female). When devising your identifier always ensure an appropriate balance between giving the reader as much information as possible about the participants and their context, and maintaining anonymity. In a study of drug misusing pregnant women in Aberdeen, the number of participants was so small that it was decided to identify women by number alone to ensure that they could not be identified. ${ }^{18}$ Unique identifiers have two main purposes. First, they show that the researcher has quoted widely from the available data. This should assure the reader that the author has not simply taken all the interesting, funny, and 'good' quotes from a limited number of interviews, focus groups or openended questions on questionnaires. Second, they help the reader to put the quote in perspective. Qualitative methods try to discover the meaning of phenomena and to place them in context. It is important to know, for example, whether a particularly negative quote about genetic screening by maternity services for disease $\mathrm{X}$ is made by a woman who
Table 1 Status of identified participants as regards (a) Huntingdon's disease and (b) history of breast and ovarian cancer

\begin{tabular}{llll}
\hline Status & Female $(n)$ & Male $(n)$ & Total $(n)$ \\
\hline HD & & & \\
Carrier & 6 & 2 & 8 \\
Non-carrier & 4 & 5 & 9 \\
$50 \%$ & 4 & 2 & 6 \\
Affected & 5 & 4 & 5 \\
Spouse & 4 & 1 & 37 \\
Total & 23 & 14 & \\
HBOC & & & \\
High & 12 & & \\
Moderate & 22 & & \\
Low & 14 & & \\
Total & 50 & & \\
\hline
\end{tabular}

HBOC, history of breast and ovarian cancer; HD, Huntingdon's disease. Table modified and reproduced, with permission, from Forrest et al. ${ }^{20}$

had undergone screening, a woman who had miscarried an affected fetus, a man with disease $\mathrm{X}$ in his family, or someone who knows nothing about disease $\mathrm{X}$.

\section{Background information on study participants}

As qualitative methods help us understand phenomena in their social context it can be useful to provide the reader with a table of background information on the study participants. It is common to list demographic details in tabular form. For example, Madi and Crow ${ }^{19}$ included a table giving respondents' ages, marital status, education and parity in a qualitative study of pregnant women's needs for information, whilst Forrest et al. provided the following overview of their interviewees' status vis-à-vis Huntington's disease and history of breast and ovarian cancer (Table 1). ${ }^{20}$

\section{Presentation of numerical data}

Quantitative studies use words to elaborate on the significance of numerical information, whereas most qualitative texts involve explaining findings in different words whether these refer to interview transcripts, video data or field notes of observations. Therefore, qualitative writing is less suited to tabular and graphical illustration. This is not to say that tables and numerical information cannot be used, for example, when a coding-down approach to qualitative analysis is used. ${ }^{21}$ For example, content analysis can involve qualitative assessment of the words or other material used. Fragments of text can be coded as negative $(-)$, positive $(+)$ or neutral $(0)$, counted and presented in a table. van Teijlingen used this method to analyse papers relating to the future of small maternity hospitals in Northeast Scotland.22 Table 2 shows that the first paper analysed did not mention anything positive or negative about general practitioner support for small maternity units, but strongly suggested that the home birth rate would go up if these units were to be closed.

\section{Grammar and readability}

When transcribing interviews and focus groups it becomes clear that people do not speak in grammatically correct

Table 2 Content analysis: papers on closure of maternity units

\begin{tabular}{lrrrrrr}
\hline Paper & \multicolumn{2}{c}{ GP support } & \multicolumn{4}{c}{ Increase in home births } \\
\cline { 2 - 7 } & + & 0 & - & + & 0 & - \\
\hline 1 & NA & 1 & NA & 5 & 2 & 1 \\
2 & 2 & 1 & NA & 3 & NA & 2 \\
3 & 11 & 2 & 1 & 3 & NA & NA
\end{tabular}

GP, general practitioner; NA, not applicable.

Table modified and reproduced, with permission, from van Teijlingen. ${ }^{22}$ 


\section{QUALITATIVE RESEARCH}

sentences. Punctuation has to be imposed and symbols agreed for marking pauses, laughter, interruptions, and so on. The authors have to decide whether to present quotes verbatim or to add words that aid the understanding and readability of a quote. Direct quotes can be disjointed and hard to read, as in the following examples from women describing their newborn babies:

"And he had bad forceps marks on his, uhm, and you ken fa'it's like [= you know what it is like], well, he had been born, uhm, and put into this [inaudible] so to speak and there was nobody there. He [husband] was distressed because the blood was coming out and he looked a bittie [= a little bit] bashed up." (Woman, age 34 years, married, third child)

"There was a photograph but he looked so bad. I thought he looked like he had been in a car crash ... [sniffing] [5second pause] But no ... because there was a bed ...I was put into this little room and I just felt so isolated and they never said [sniffing]." (Woman, age 23 years, single, first child)

Similarly, authors have to decide whether to include or partially translate regional dialects. The only rules are that the reader should understand what is being said and the researcher should make plain as in the above examples what has been added or changed for the publication.

\section{Presentation of translated material}

The use of an interpreter may have a significant effect on interviewees, the research process and findings ${ }^{23}$ (E Pitchforth and E van Teijlingen, unpublished observations). Presenting findings in a different language from that in which the data were collected also presents challenges. One of the authors (E.P.) relied on an interpreter for a study of obstetric care in Bangladesh. Interviews were conducted in Bangla and transcribed and translated into English. When another translator provided an alternative meaning in places, the author acknowledged these differences but chose to present the findings from the initial translation. ${ }^{24}$ Decisions regarding the use of an interpreter and translated language must be made explicit. Strong local dialects or words for which there is no equivalent in English can be left and a glossary provided.

\section{Being transparent}

As a key strength of qualitative research is its ability to "acknowledge bias, value it and make its impact on the research process as explicit as possible", 9 transparency of the research process is very important. No matter how you choose to use data to support your argument, the systems you use to arrive at interpretations must be explicit. ${ }^{13}$

\section{Reflexive writing}

In order to produce a reflexive account the researcher should self-consciously assess the likely impact of the methods used on the data obtained. ${ }^{25}$ Sufficient data should be included in the report so that readers can assess for themselves whether analytical criteria have been met. Mays and Pope point out that personal and intellectual biases affect the choice of topic and approach (also true of quantitative studies, of course), whilst age, sex, language, social class and professional status affect the 'distance' between the researcher and those researched and need to be acknowledged and possibly discussed. ${ }^{25}$

The reflexive researcher should also consider ethical issues, including confidentiality and the consequences of the research for those participating. Sometimes an interview can be an enlightening and cathartic experience for respondents but sometimes it can be distressing both for the researcher and the researched. When respondents' behaviour or expectations are changed by the research process, the researcher must acknowledge this effect and any steps which have been taken to mitigate damage.

\section{Final remarks}

This paper completes the series on conducting qualitative research in family planning and reproductive health. Writing up and disseminating research findings are vital stages in the research process but can be challenging, especially in achieving publication in peer-reviewed journals. This emphasises the importance of treating writing not as a final stage in the research process but as part of the analysis and interpretation of data. Examples are given of different ways in which data can be used to support coherent arguments, and choices faced over the presentation of direct quotes or translated materials are described. As in the previous papers, the need to be explicit in any decisions made, either in methodology or writing up, is highlighted.

Statements on funding and competing interests

Funding. Karen Forrest Keenan has been employed on two Wellcome Trust grants working on qualitative research projects. Maureen Porter is funded on a different Wellcome Trust grant. Emma Pitchforth has been funded by NHS RARARI, University of Aberdeen, Carnegie Trust Scotland and the Phil Strong Memorial Prize (British Sociological Association's Medical Sociology Group).

Competing interests. None identified.

References

1 Richardson L. Writing Strategies: Reaching Diverse Audiences. Newbury Park, CA: Sage Publications, 1990.

2 Wolcott H. Writing Up Qualitative Research. Newbury Park, CA: Sage Publications, 1990 .

3 Potter J, Wetherall M. Analysing discourse. In: Bryman A, Burgess R (eds), Analysing Qualitative Data. London, UK: Routledge, 1994

4 Rice P, Ezzy D. Qualitative Research Methods: A Health Focus. Melbourne, Australia: Oxford University Press, 1999.

5 Robinson I. Personal narratives, social careers and medical courses: analysing life trajectories in autobiographies of people with multiple sclerosis. Soc Sci Med 1990; 30: 1173-1186.

6 Kumar S, Little P, Brown N. Why do general practitioners prescribe antibiotics for sore throat? Grounded theory interview study. $B M J$ 2003; 326: 138.

7 http://bmj.bmjjournals.com/advice/special_methods.shtml\#quality [Accessed 27 January 2005].

8 Bowling A. Research Methods in Health (2nd edn). Buckingham, UK: Open University Press, 2002.

9 Forrest Keenan K, van Teijlingen E. The quality of qualitative methods in family planning and reproductive health care J Fam Plann Reprod Health Care 2004; 30: 257-259.

10 Marvasti AB. Qualitative Research in Sociology. London, UK: Sage Publications, 2004.

11 Leppard M. Obstetric care in a Bangladesh district hospital: an organizational ethnography. $\mathrm{PhD}$ thesis, London School of Hygiene and Tropical Medicine, London, UK, 2000.

12 Silvernam D. Telling convincing stories: a plea for cautious positivism in case studies. In: Glassner B, Moreno $\mathrm{J}$ (eds), The Qualitative-Quantitative Distinction in the Social Sciences. Dordrecht, The Netherlands: Kluwer, 1989; 57-77.

13 Mason J. Qualitative Researching (2nd edn). London, UK: Sage Publications, 2002.

14 Eyesenbach G, Kohler C. How do consumers search for and appraise health information on the world wide web? Qualitative study using focus groups, usability tests, and in-depth interviews. BMJ 2002; 324: 573-577.

15 Murray SF. Relation between private health insurance and high rates of Caesarean section in Chile: qualitative and quantitative study. $B M J$ 2000; 321: 1501-1505.

16 Murray S, Grant E, Grant A, Kendall M. Dying from cancer in developed and developing countries: lessons from two qualitative interview studies of patients and their carers. BMJ 2003; 326: 368-372.

17 Murray SA, Boyd K, Kendall M, Worth A, Benton TF, Clausen H. Dying of lung cancer or cardiac failure: prospective qualitative interview study of patients and their carers in the community. BMJ 2002; 325: 929-933. 
18 Teijlingen van E, Hall J, Campbell D, Mitchell E, Fulcher F. Drug misusing pregnant women's experience of care: a qualitative study. A report funded by the Chief Scientist Office Small Grant Scheme. Aberdeen, UK: University of Aberdeen, http://www.show.scot.nhs.uk/cso/Publications/ExecSumms/MayJune 04/van\%20Teijlingen.pdf [see Summary].

19 Madi B, Crow RA. A qualitative study of information about available options for childbirth venue and pregnant women's preference for place of delivery. Midwifery 2003; 19: 328-336.

20 Forrest K, Simpson SA, Wilson BJ, van Teijlingen ER, McKee L, Haites $\mathrm{N}$, et al. To tell or not to tell: barriers and facilitators in family communication about genetic risk. Clin Genet 2003; 64: 317-326.

21 Forrest Keenan K, van Teijlingen E, Pitchforth E. The analysis of qualitative research data in family planning and reproductive health care. J Fam Plann Reprod Health Care 2005: 31: 40-43.

22 van Teijlingen ER. A social or medical model of childbirth? Comparing the arguments in Grampian (Scotland) and the Netherlands. PhD thesis, University of Aberdeen, Aberdeen, UK, 1994.

23 Jentsch B. The 'interpreter effect': rendering interpreters visible in cross-cultural research and methodology. J Eur Soc Policy 1998; 8: 275-289.

24 Pitchforth E. Emergency obstetric care: needs of poor women in Bangladesh. PhD thesis, University of Aberdeen, Aberdeen, UK, 2004.

25 Mays N, Pope C. Qualitative research in health care: assessing quality in qualitative research. $B M J 2000$; 320: 50-52.

\section{MEMBERSHIP OF THE FACULTY OF FAMILY PLANNING AND REPRODUCTIVE HEALTH CARE}

The MFFP Examination consists of:

Part 1 (A or B) New format Multiple Choice Question paper (MCQ)

Part 1A Examination: For those who have not passed the Part 1 MRCOG nor received exemption from Part 1 MRCOG. This 2-hour paper consists of $60 \mathrm{MCQ}$ s based on basic, applied and clinical science.

Part 1B Examination: For those who have passed the Part 1 MRCOG or have received exemption from Part $1 \mathrm{MRCOG}$ and wish to be exempt from the basic science component of the Part 1A. This 11/2-hour paper consists of 45 MCQs based on clinical and applied science.

Part 1 (A and B) examinations will be held on Friday 21 October 2005 (applications must be received by 1 July 2005).

\section{Part 2 Examination (Dissertation or Case Reports)}

Part 2 - Dissertation or Case Reports

Submission of one Dissertation (10 000 words) or two Case Reports (2500 \pm 500 words each).

Approval of the Dissertation or Case Reports titles by the Dissertation/Case Reports Convenor must be obtained before the candidate starts work on the Dissertation or Case Reports and before the candidate applies to sit the Part 2 (CRQ, MEQ, OSCE) component. Guidance notes and proposal form, plus exemption form/information, are available on request (see below).

\section{Part 2 Examination (CRQ, MEQ, OSCE)}

\section{Part 2 - CRQ, MEQ, OSCE}

Critical Reading Question examination paper (CRQ)

Modified Essay Question examination paper (MEQ)

Objective Structured Clinical Examination (OSCE)

Applications for the Part 2 held in June 2006 must be received by 1 December 2005.

\section{Please consult the revised Examination regulations for changes to entry requirements.}

The qualification is subject to re-certification every 5 years.

Revised regulations (June 2004), application forms and dissertation documents are available on application to: Miss Denise Newell, Examination Secretary, Faculty of Family Planning and Reproductive Health Care of the Royal College of Obstetricians and Gynaecologists, 27 Sussex Place, Regent's Park, London NW1 4RG, UK. Tel: +44 (0) 207724 5629. Fax: +44 (0) 2077235333. E-mail: denise@ffprhc.org.uk. Website: www.ffprhc.org.uk 